does not affect its colloid osmotic pressure (not more, incidentally, than the diminution of body size). It seems, therefore, that the colloid osmotic pressure of the body fluids of an animal reflects merely the total of its general organisation, the sum of all particular modifications, progressive and regressive, which have appeared during its evolution.

Station maritime de Biologie,
Tamaris-sur-Mer,
Laboratoires Lumière, Lyon.

Paul Meyer. Jan. 15.

1 NATURE, 136, 757 (1935). Compt. rend. Soc. Biol., 120, 303, 305 (1935).

\section{Diet and Colour of Birds}

DURING the past year (1935), work was begun to improve the feeding routine of all animal groups at the Zoological Garden in Philadelphia. Efforts are being made to devise food mixtures that are complete in all known essentials, contain a wide variety of materials and allow for seasonal abundance so as to be economical, and are similar in general physical characters to natural foods. From time to time, various factors have necessitated modifications of formulæ, so that complete descriptions of the diets to which reference will be made are better postponed. Eventually records of these studies will be used as the subject matter of a report on methods of feeding wild animals in captivity. In spite of the present incompleteness of the investigation, however, certain effects of changes in diet upon the colours of the plumage of several species of birds seem worthy of record at this time.

It is common knowledge that some species of birds tend to lose colour more or less completely when they are exhibited in zoological gardens. There have been many instances of this change among the avian collection of the Zoological Society of Philadelphia, the more conspicuous examples being the flamingos (Phonicopterus ruber), scarlet ibises (Eudocimus rubra) and roseate spoonbills (Ajaia ajaia). Under former conditions, the natural colours of these birds began fading with the first moult in captivity. After completion of the second or third moult, the plumage contained practically none of the red colours, and beaks and legs became dirty grey and scaley.

The usual routines of feeding these and other species of birds in zoological gardens naturally omit many elements which serve as food in the wild. At the same time, modern knowledge of nutrition has not been extensively utilised in planning diets. Accordingly, faded plumage may be regarded as evidence of malnutrition.

At the Zoological Garden in Philadelphia, the flamingos, scarlet ibises and roseate spoonbills are exhibited in a large indoor cage, together with ducks, geese, pheasants, sea bulls, gallinules, bitterns and a number of passeriformes. Prior to June 1935, food for this group consisted of chopped meat and fish, cracked corn and wheat, boiled rice, millet and canary seed and chopped apples, bananas and lettuce. The amounts of the different foods were not standardised, so that proportionate parts cannot be stated. The various materials are listed to show availability. Most of the birds in this group, including the varieties mentioned, were known to take portions of each food offered, but records of preferences and consumption were not made.
On June 20, 1935, the diet for the group of birds with which the flamingos, ibises and spoonbills were exhibited was changed to one which supplied a greater variety of proteins, including those from milk and certain legumes, more abundant minerals, especially calcium and phosphorus, and much greater amounts of the fat-soluble vitamins.

At this time there were four flamingos, four scarlet ibises and two roseate spoonbills in the group. These birds began moulting within three months after the food was changed. During the first week of September there appeared to be a slight recolouring of some of the specimens, a change that has progressed, so that after approximately six months on the new rations colours are much more distinct. The feathers of one flamingo are light pink throughout, except, of course, the black primaries, and the beak and legs are also coloured. Coloured feathers in the other three flamingos are confined chiefly to the wing coverts, but the legs are becoming pink and are much less scaley than formerly. The scarlet ibises and roseate spoonbills have reacted more uniformly than have the flamingos. Although there are individual variations, all individuals show a partial return of the natural colours. At the same time, the beaks of the scarlet ibises have lost much of their former black, scaley appearance and the legs are becoming coloured also.

Comparable changes have been made in the feeding routine for many other species of birds, and in general results are satisfactory, other instances of improved coloration being observed. Two of these may be mentioned because there were opportunities for comparison with individuals on the standard diet.

The indigo bunting, Passerina cyanea, and the nonpareil bunting, $P$. ciris, formerly were fed with canary seed, fine millet and white millet, with occasional allowances of apple and lettuce. On May 10, 1935, these grains were replaced by mixed foods that were essentially the same as those already mentioned for the first group. The colours in the winter plumage of male indigo buntings, which developed after the change in diet, are typical of the species, instead of ths slate grey usually found on birds fed with the seed ration. The depth of colour in the plumage of male nonpareil buntings has also strikingly improved. Particularly noticeable is the deep red of the breast. Formerly this colour was much diluted with yellow.

Which one of the factors, or which combination of factors supplied by the new foods and lacking in the former mixtures, influences the colour or plumage remains to be determined.

HERBERT L. RATCLIFFE.

Penrose Research Laboratory of the

Zoological Society of Philadelphia, and Department of Pathology, University of Pennsylvania.

Jan. 21.

\section{Estimation of Vitamin A}

THE correspondence upon this subject which has appeared in NATURE during the last few weeks has directed attention to the extremely unsatisfactory state which those of us who are interested in the matter from a commercial as well as from a scientific aspect have long known to exist.

Although the spectrographic is an accurate and reproducible method of determining vitamin $\mathbf{A}$, in order to eliminate the possibility of the presence of 
a second absorbing factor at $\lambda 3280 \mathrm{~A}$., the biological test is a necessary check on the physical. It is also a necessity, since it is the biological action of vitamin A which determines its value. (Incidentally, it has been found in this laboratory that while the crest of the absorption band for high vitamin oils lies at $\lambda 3280$ A., that for certain concentrates, some of them of extremely high vitamin content, lies farther in the ultra-violet in the region of $\lambda 3130 \mathrm{~A}$.).

The modern biological test depends upon the measurement of growth, but it is at least doubtful whether vitamin $\mathbf{A}$ is primarily a growth-promoting vitamin. It seems possible that the healthy state of epithelial and absorbing surfaces, induced in the animal by vitamin $A$, enables the absorption of the true growth vitamin, whether present in the oil or in the supposed vitamin-free ration. Some such argument as this might explain the varying factors used in different laboratories for converting spectrographic values to biological. These factors cover a range of 100 per cent, varying as they do from 1100 I.U. to 2113 I.U. for each $E 1$ per cent

Further disturbing factors are :

(1) The U.S. 'Reference' oil, on which the majority of tests have been based, is an abnormal oil. The ratio of vitamin $A$ to vitamin $D$ in this oil is given as 3000-95 I.U., which is most unusual in a cod liver oil.

(2) Are we sure that the 'Reference' oil now in use is the same oil it has always been ? If so, it must have remarkable keeping qualities ; and if not, what published tests are there of its successor ?

(3) In the biological test on this oil, have sufficient precautions been taken to ensure that the rations used in different laboratories are strictly comparable?

The recent availability of supplies of pure $\beta$ carotene should lead to a clearing up of the matter provided the material in question is really standard in composition and gives uniform results.

With regard to the previous correspondence in respect to the 'Reference' oil, may we say that we are in hearty agreement with the suggestion made by Bacharach, Drummond and Morton, that all subsidiary standards should have their spectrographic assay stated as well as their biological, and that their keeping properties should be checked regularly by the spectrograph.

Everyone admits the importance of vitamin $\mathbf{A}$ in everyday life, and the task of the manufacturer of vitamin A products who endeavours to supply a genuine article would be enormously assisted if a satisfactory solution of this problem could be previded in the near future.

\section{JOHN F. WARD.}

Crookes Laboratories, R. T. M. HAINES.

London, N.W.10. Feb. 17.

\section{The New Ergot Alkaloid}

DuRING the first half of the year 1935 communications appeared from four different laboratories, in three different countries, each describing the dis. covery and isolation of a new alkaloid from ergot, very different in its properties from those previously known. These communications dealt with researches which had been proceeding concurrently and independently, and in each case the authors gave a name to the alkaloid which they had obtained, so that four new names were put forward-Ergometrine $^{1}$, Ergotocin ${ }^{2}$, Ergobasine ${ }^{3}$ and Ergostetrine ${ }^{4}$.

There was an obvious general resemblance between the substances thus variously named, but preliminary analytical indications, and certain minor discrepancies in the earlier published physical constants and chemical properties, left some doubt as to whether the four were really identical, or only closely related alkaloids. Later and more detailed publications have removed most of these discrepancies. It appeared to us, however, that the question of identity ought to be settled finally by an exchange of specimens, a careful comparison of them in the laboratories concerned, and, if possible, an agreed statement of the resulting conclusion. This exchange and comparison have now been carried out by the undersigned, of whom H. King has acted in the place of the late H. W. Dudley (who died on October 3, 1935).

Our comparisons of the melting points and mixed melting-points of the four alkaloids and of certain of their salts, and of their optical activities in different solvents in cases where sufficient material was available, leave us in no doubt that the alkaloid obtained in the four different laboratories was the same substance, and that the four names given to it are synonyms. Having reached that conclusion, we are content to leave to the world of science the choice of one of these names, for adoption into scientific literature as the recognised name of the one alkaloid.

$$
\begin{aligned}
& \text { M. S. KHaRasch. } \\
& \text { H. King. } \\
& \text { A. Stoll. } \\
& \text { MaRvin R. Thompson. }
\end{aligned}
$$

1 Dudley, H. W., and Moir, C., (Ergometrine), Brit. Med. J., 1 , 520 (1935); S Science, 81, 559 (1935). Dudley, H. W., (Ergometrine), Proc. Roy. Soc. London, B, 810, 116, 478 (1935).

'Kharasch, M. S., and Legault, R. R. (Ergotocin), Science, 81, 388 and 614 (1935); J. Amer. Chem. Soc., 57, 956 and 1140 (1935). Davis, M. E., Adair, F. L., Rogers, G., Kharasch. M. S., and Legault, R. R. (Ergotocin), Amer. J. Obstet. Gynaec., 29, 155 (1935). 3 Stoli . R. (Ergotocin), Amer. J. Obstet. Gynaec., 29, 155 (1935). 1680 (1935): Bull. Sci. Pharmacol., 42, 257 (1935)

4 Thompson, M. R. (Ergostetrine), J. Amer. Pharm. Assoc., 24, 24 and 185 (1935); Science, 81, 636 (1935).

\section{A Small Chemical Separation of the Chlorine Isotopes}

A SMall chemical separation of the chlorine isotopes has been observed by heating carbon tetrachloride with sodium amalgam, when the reaction

$$
4 \mathrm{Na}+\mathrm{CCl}_{4}=\mathrm{C}+4 \mathrm{NaCl}
$$

occurs almost quantitatively ${ }^{1}$ and the light isotope reacts preferentially. Carbon tetrachloride (A.R.) was fractionated eight times (twenty-four fractions) and the densities of the middle fractions after drying with purified phosphorus pentoxide were compared by the flotation method, using a cylindrical pyrex float. After four successive fractions the density became constant. The float was controlled by means of a small piece of enclosed soft iron. The groundstoppered vessel containing the carbon tetrachloride was placed in an outer vessel containing phosphorus pentoxide and supported by brass clamps in a thermostat at $23^{\circ}$. An intermittent Gouy regulator ${ }^{2}$ controlled the temperature, which was read on a Beckmann thermometer by a travelling microscope reading to $0.002 \mathrm{~mm}$., so that $0.00025^{\circ}$ could be easily read. The thermometer varied $0.00019^{\circ}$ per $\mathrm{mm}$. with change of pressure. The velocity of the float varied linearly with temperature, $0.001^{\circ}$ in set point corresponding with a density change of $1.9 \times 10^{-6}$ and a velocity change of $0.0024 \mathrm{~cm}$. per sec. 